\title{
The Wellness Recovery Action Plan (WRAP): Effectiveness with Chinese consumers
}

\author{
Wenli Zhang, Suet Yi Wong, Yanbing Li, Hong-Shiow Yeh and Yue Zhao
}

Bo Ai She - Chinese Mental Health Consumer Self-Support Organisation, Auckland, New Zealand.

\begin{abstract}
Education and knowledge have always been prized life quests for Chinese. The question however, is whether Western-style mental health education is acceptable to Chinese mental health consumers and whether it is useful in improving their knowledge and understanding of mental health and the process of recovery. Whilst there has been a plethora of psychoeducational material published, most offer passive learning or require little educator/learner interaction, let alone active participation.
\end{abstract}

The aim of this paper is to present a pilot research on the acceptability, the applicability and the effectiveness of the Western concept of mental health recovery including the Wellness Recovery Action Plan (WRAP) programme in improving the effectiveness of recovery among the members of Bo Ai She (BAS), a Chinese mental health consumers' self-help organisation in New Zealand.

Qualitative research methods were used to undertake this research. Eight members of BAS and three professional mental health workers were interviewed, and proceedings from discussions in two focus groups comprising consumers and their family members have been included to form the data base.

Key findings from this research affirmed that the WRAP programme has played a significant role in recovery for Chinese consumers in BAS. The results also suggested areas which needed to be modified in order to become a cultural-appropriate programme in Chinese mental health consumers' recovery.

\section{Introduction}

The Wellness Recovery Action Plan (WRAP) programme designed by Mary Ellen Copeland is to help people who have suffered from mental health issues to rebuild their pathway to recovery (Copeland, 2003, 2004; Kane \& Blank, 2004). This programme contains two important parts: 1) five key concepts of mental health recovery (hope, personal responsibility, education, self advocacy and support) and, 2) six self-management systems (wellness tool box, daily maintenance plan, triggers and plan, early warning signs and plan, when things 
have broken down and plan, and a crisis plan) (Copeland, 2003). WRAP has been widely recognised as an effective personalised recovery programme as evidenced by mental health consumers who have completed this programme (Copeland \& Mead, 2004; Pocklington, 2007).

In New Zealand, the WRAP programme was introduced to mental health consumers in 2000 and to Chinese consumers in 2002 (Anderson, Lidstone \& Zhang, 2005). BAS, a Chinese consumer peer support group, was established after members participated in the WRAP programme and continued their recovery journey in group supports (Zhang \& Wong, 2006). Members of BAS were observed in making positive changes in their lives. Comments from their family members and mental health professionals were positive.

An evaluation on the outcome of WRAP workshops suggested that the programme had made significant changes in the attitudes and knowledge about the concept of recovery from mental health professionals and consumers in New Zealand (Doughty, Tse, Duncan \& McIntyre, 2008). Although there were anecdotal reports of success in learning and utilising WRAP from Chinese consumers, this information remained subjective. The participation of BAS in a practitioner research project described below provided a platform for BAS to undertake an evaluation on the effectiveness of the WRAP programme in order to create evidence-based social practice.

The purpose of this research was to investigate the effectiveness of the WRAP programme among Chinese consumers. Two main questions needed to be asked: Has this Western-style mental health recovery programme been useful to help Chinese consumers to recover? Is there any need to adapt this programme in order to make it culturally appropriate for Chinese consumers? It is expected that the outcome of this research will help to develop a more culturally appropriate programme to assist with recovery in Chinese consumers. It will also be useful to provide evidence-based practice in order to support future funding applications and to offer this programme to Chinese consumers, family members and mental health professionals.

\section{Methodology}

This research could not have been done without the support of the Growing Research in Practice (GRIP) project. GRIP was set up by academics from Massey University and The University of Auckland to facilitate 'practitioner research' which is carried out by practitioners using the information and research questions arising from practice to inform and improve practice (Beddoe, et al., 2007; Lunt, Fouché \& Yates, 2008). The GRIP team allocated two mentors and helped BAS formulate a research team which is comprised of a group of volunteers from mental health and research professionals and BAS committee members.

A qualitative research method was utilised to undertake this study. The researchers developed semi-structured questionnaires for interviews with individuals and discussions in focus groups. A focus group was arranged to discuss the purpose of the proposed research and the importance of ownership of this research by BAS members. The positive response from members was overwhelming. Voluntary participants from members received a written information sheet in Chinese and a consent form to sign. 
The research intended to evaluate the effectiveness of the programme among Chinese from the aspect of both content and process. Questionnaires included the consumer's personal profile and six semi-structured questions. Questions about the content included which parts of the programme were most useful to them, and how the programme influenced their lives. The questions about the process were to do with when and how they first learned about the WRAP programme, how long they had been using the WRAP programme, whether they had shared their plan with others and what they thought needed to be changed in order for them to learn and use the programme. The questions for the family focus group included: when and how they had learned about the WRAP programme, what changes they had noticed in their family member and if they too would like to learn the WRAP programme. The professionals interviewed were asked when and how they had learned about WRAP, what changes they had observed in their clients, and whether they wanted to know more about the programme.

\section{Participants' profiles}

In order to collect information from various resources, individual consumers who had participated in the WRAP programme, mental health professionals and family members were interviewed individually and in group settings. Eight voluntary consumers and three mental health professionals (Table three) were interviewed individually. For the consumers' demographic profiles see Table one and for the clinical profile of consumer participants refer to Table two. Six family members (Table four) and five consumers participated in two focus group discussions respectively. The consumer focus group consisted of five females.

Table one. Demographic profile of consumer participants.

\begin{tabular}{ccccccccc}
\hline & Age range & \multicolumn{9}{c}{ Gender } & Ethnicity & \multicolumn{3}{c}{ Years in NZ } \\
$25-35$ & $36-60$ & $>60$ & M & F & Chinese & $<10$ & $10-20$ & $>20$ \\
2 & 4 & 2 & 2 & 6 & & 2 & 3 & 3 \\
\hline
\end{tabular}

Table two. Clinical profile of consumer participants.

\begin{tabular}{ccccccc}
\hline & Diagnoses & \multicolumn{2}{c}{ Years of illness } & \multicolumn{2}{c}{ Hospitalised } \\
Depression & Schizophrenia & Bipolar & $<10$ & $>10$ & Yes & No \\
5 & 2 & 1 & 6 & 2 & 7 & 1 \\
\hline
\end{tabular}

Table three. Profile of mental health professionals.

Gender

Male Female Psychiatric registrar

0
1
Professions

Community support worker

1
Mental health nurse 1 
Table four. Profile of family members.

Gender

Male Female

\section{Relationships to consumers}

Mother Husband

3 
A few consumers reported that they were able to develop adherence to their medication.

I would increase the dosage of my medication a little bit if I really couldn't sleep. It can help improve the situation.

Self-advocacy

Consumers reported that they felt more confident to ask doctors questions and to talk to doctors about their needs. The same observation was reported from professionals:

They are more confident to tell you what they want and they are actually more able to voice their needs.

Support

All participants expressed that they were able to get more support and were willing to seek help when they needed it. Some of them reported that their relationships with others have improved as well:

My attitude towards others has changed, (I now) know how to make a proactive approach (to others).

(I) talk to my family and then they are more patient with me.

I have more verbal communication with others; I learned from my family that I was doing much better than before.

Participants actually showed they were more actively able to seek help. One consumer said:

When I felt unwell I would find someone to talk to.

Professionals also reported they had observed that those consumers who had participated in the WRAP programme appeared to support each other more. Compared with other consumers they tended to be closer to each other.

\section{Utilisation of the self-management system}

Most participants reported that all parts of WRAP were useful, which included:1) developing wellness tools, 2) detecting the triggering events, 3) being aware of early warning signs and 4) practising a daily maintenance plan and 5) having a crisis plan. Most of the participants reported that their life became more stable and the symptoms had reduced, the dosage and frequency of their medication having reduced as well.

Developing a wellness toolbox

All consumer participants stated that developing wellness tools was very useful for them to manage their wellbeing.

Every time I felt I was getting sick, I phoned and talked to my friend. I'd get better. I also watch photos of happy times (to cheer myself up). Having good memories helps me to forget my worries.

A hot bath, listening to music and singing songs also help me to forget unhappiness. 
Detecting the triggering events

During consumer group discussions, a few people shared the benefit of knowing what his/ her triggers were.

As I was able to identify the things that might cause me to feel sad or unhappy, I could find ways to avoid that or do something else to get rid of those bad feelings.

Being aware of early warning signs

Many consumers commented that they could avoid a crisis situation happening because they could take action at an early stage.

I have gained a good understanding of my symptoms; therefore I can recognise them and manage them in time.

I can recognise the symptoms of relapse; I have made a plan for myself. For example, (I) keep eating healthy food, have regular exercise, and talk to someone when I am not feeling well.

Practising a daily maintenance plan

Most consumer participants reported that they practised their personal plan daily and it was helpful.

Since I've practised the maintenance plan daily, I do not have signs of illness. My life is fulfilling.

\section{Crisis plan}

Two consumers reported that they used the crisis plan when their emotional states were not stable and that it was helpful. One professional noticed that one of her patients who was in hospital behaved differently since he learned the WRAP programme.

He had more insight about his symptoms, was more cooperative, and more compliant with the medication. He has made a plan to be home, to be independent. He will ask if he needs help.

The above findings indicated that Chinese consumers were able to set up a personalised self-management system and it has helped in their recovery.

\section{Implementation of the programme}

\section{Knowledge of the WRAP programme}

The length of utilising the WRAP plan by the participants varied from three months to three years. All learnt the programme in a group setting. Some had participated more than once in the programme. During the research interview, most of them still remembered details of the programme. Only one consumer participant reported that she had attended a WRAP group but couldn't remember any details of the programme as her mental health was not stable at that time. However, she reported that she was able to communicate with a member in her WRAP group and gained comfort and encouragement.

None of the family members and the mental health professionals from this research had attended any WRAP training workshops. Two of them learnt about WRAP from their clients and one of them personally had bought the WRAP book. One of them had no knowledge of WRAP prior to the interview. 


\section{Sharing of the personal WRAP plan}

Most consumer participants shared their personal recovery plan with other members in BAS. Some of them used their personal experiences to help new members to develop their personal plans.

One consumer expressed that she shared her plan with the family and her family members gained a better understanding, more patience towards her and gave her more encouragement. None of the consumers had shared his/her personal plan with professionals.

Overall, the feedback about the effectiveness of the WRAP programme was strongly positive. Learning the WRAP programme had helped participants have a more positive attitude and understanding of mental health and recovery. It has increased consumers' awareness of their personal responsibility, willingness of self-advocacy and ability in getting support.

\section{Suggestions for change}

Consumers, family members and professionals all contributed suggestions to adjust the WRAP programme in order to suit Chinese consumers' needs. The suggestions from consumers included:

- The need to use simple language and not too much jargon

- Introducing more Chinese-style wellness tools

- Having longer sessions or more sessions

- Giving more explanations about the content

- Using the media for promotion so that the programme is more accessible for consumers outside BAS and for members of the public

- Family members to participate in learning WRAP.

Four out of six family member participants responded that they would like to attend the WRAP training. They suggested that consumers need more individual assistance in developing their personal plans. They felt that a copy of the WRAP programme should be made available to the family member to help the consumer communicate with doctors about the WRAP plan.

All professionals wanted to know more about the programme. They would like to have a copy of the consumer's WRAP crisis plan in their clinic file. They believed that the programme could be great for helping the consumer if the consumer became unwell and required professional attention.

It would give us a better understanding about him as a person, about his values.

In a crisis, professionals can protect clients' rights if they know the consumers' standing instructions as to what (treatment) they want (for themselves should they be unwell and losing insight).

One common suggestion from consumers, family and professionals was that all parties were keen to learn the WRAP programme but currently there is much to be bridged before the WRAP programme training can be provided to family members and professionals. 


\title{
Conclusion and further actions
}

Although introduced from the Western-style, the Mental Health Recovery programme including the WRAP programme has had a significant influence on the journey of recovery for Chinese consumers.

Adaptation of a programme of Western cultural origin would also have the benefit of bridging the different cultural attitudes between Chinese consumers and Western-trained professionals, reducing the distance, facilitating sharing, cooperation, acceptance and more importantly mental health.

The journey of recovery is a joint effort made by the consumers, their family members and the professionals. A buddy system for individual members and a system to ensure all the members of a new WRAP group make a copy of their crisis plan to share with their clinical professionals will be introduced to future WRAP programme participants.

Finally, the research group will report the findings to the participants and the members of BAS. The consumers have ownership of the WRAP programme and the outcome of this research. The committee will continue to evaluate and improve the effectiveness of the programme with Chinese consumers.

\begin{abstract}
Acknowledgements. This research was sponsored by the GRIP project and mentored by Associate Professor Christa Fouché, Massey University (now at The University of Auckland), Dr Neil Lunt, senior lecturer, Massey University (now at the University of York) and Deborah Yates, project manager. Their great guidance and enormous support throughout the project contributed to the success of this research. Tribute must also be paid to the Committee and members of Bo Ai She, and to the family members of Chinese consumers for their great courage and openness in sharing their experiences which furnished a rich data-base for this project. Also, thanks are given to the mental health professional workers who provided their own valuable information. Finally, appreciations go to the research team/volunteers, with their unconditional commitments and sacrifice of their valuable time making this project valuable and meaningful.
\end{abstract}

The authors wish to acknowledge the GRIP programme and the funding that made the GRIP projects possible: the Families Commission's Innovative Practice Fund, the Ministry of Social Development's SPEaR Linkages fund and the ASB Trusts in partnership with the ANZASW and The University of Auckland Faculty of Education and Staff Research Funds.

*Correspondence to: Wenli Zhang MEd (Counselling), RSW, MANZASW, MNZAC wenli.zhang@pgfnz.org.nz

\section{References}

Anderson, B., Lidstone, N., \& Zhang W. (2005). A pathway to recovery for Chinese consumers in New Zealand, Presentation in the Fourth Pan-Asian Pacific Conference on Mental Health 2005, Shanghai, China.

Beddoe, L., Fouché, C., Harington, P., Light, G., Lunt, N., \& Yates, D. (2007). Growing research in practice: The story so far. Social Work Review, 19(1), 39-50.

Copeland, M. E. (2003). Mental health recovery including wellness recovery action planning: Facilitator training manual. Vermont: Peach Press.

Copeland, M. E., \& Mead, S. (2004). Wellness recovery action plan and peer support-Personal, group and program development. Dummerston, Vermont: Peach Press.

Doughty, C., Tse, S., Duncan, N., \& McIntyre, L. (2008). The Wellness Recovery Action Plan (WRAP): Workshop evaluation. Australasian Psychiatry, 16(6) 450-456.

Fouché, C., Lunt, N., \& Yates, D. (2007). Growing research in practice: A collection of resources. Massey University: Auckland. Available at: http: / / www.education.auckland.ac.nz/uoa/grip-publications 
Growing Research in Practice website: http: / / www.education.auckland.ac.nz/uoa/home/ about/schools-departments/chsswk/grip

Kane, C. \& Blank, M. B. (2004). NPACT: Enhancing programs of assertive community treatment for the seriously mentally ill. Community Mental Health Journal, 40, 549-559.

Lunt, N., Fouché, C., \& Yates, D. (2008). Growing research in practice: An innovative partnership model. Wellington: New Zealand Families Commission. Retrieved on 20 February 2010. http: / / www.nzfamilies.org.nz/ research/ growing-research-in-practice-grip

McIntyre, L. (2006). WRAP around New Zealand: Evaluation of workshops on Wellness Recovery Action Planning. Paper presented by Mary Ellen Copeland MS, MA.

Pocklington, S. (2007). Wellness Recovery Action Planning: The essence of a new paradigm. Mental Health Recovery Newsletter, 8(1), 1-3.

Zhang, W., \& Wong, S. (2006), Innovative group approach: Bo Ai She: A Chinese mental health consumer peer support group. Paper presented at the fifth International Conference on Social Work in Health and Mental Health, Hong Kong, China. 